\title{
Exploring the Concept and Incentives of Sustainable Business Models
}

\author{
Annabeth Aagaard* and Peter Lindgren \\ Aarhus University, Department of Business Development \& Technology \\ Birk Centerpark 15, 7400 Herning, Denmark \\ E-mail: \{aaa; peterli\}@btech.au.dk \\ *Corresponding Author
}

Received 9 March 2016; Accepted 10 March 2016; Publication 25 April 2016

\begin{abstract}
The terminology and concept related to sustainable business models (SBM) has received increasing attention over the last decade, as the "BM.com era", sustainable innovation and open innovation concepts have become more popular and of growing global relevance. However, studying SBMs does present certain challenges due to lack of clear definitions and empirical studies. The objective of this study is to present and discuss different approaches towards mapping and understanding SBMs and the incentive models behind. Thus a key contribution of this paper is an exploration of the concept and the incentives of SBM to provide new angles to SBM research.
\end{abstract}

Keywords: Sustainable and non-sustainable business models, open business models, closed business models.

\section{Introduction to the Business Model Cube}

Business model (BM) and Business Model Innovation (BMI) has been the focus of substantial attention by both academics and practitioners (Amit \& Zott, 2001; Chesbrough \& Rosenbloom, 2002; Christensen \& Raynor, 2003; Govindarajan \& Trimble, 2005; Markides \& Charitou, 2004; Markides, 2008; Zott, 2011; Teece, 2012; Lindgren \& Aagaard, 2014) and has been the subject

Journal of Multi Business Model Innovation and Technology, Vol. 4, 35-46.

doi: 10.13052/jmbmit2245-456X.412

(C) 2016 River Publishers. All rights reserved. 
of a still growing number of academic and practitioner-oriented studies. Current rates of change are intensifying and involve a growing number of co-dependent dynamic variables (Inyang et al., 2011). Greater global interconnectedness, technologically enabled transparency, customer transience and cultural diversity have all converged (Rosethorn, 2009; Garavan \& McGuire, 2010; He, 2012), generating market pressures businesses can no longer ignore. With new demands and the quest for competitive advantage is still a dominant driver (He, 2012), organizations are being forced to find new ways to achieve success.

In order to stay competitive, organizations are under pressure to respond to social changes (Wang, et al., 2011) and sustainable business (SB) and sustainable business model innovation (SBMI) is suggested as a new and different perspective on business. Over the last decade, research on SBs and - innovations has expanded rapidly. Sustainability has become a new premise for doing business (Aagaard, 2012) - moving it from political discourses into business boardrooms. However, applying BMI as a way to create sustainable value requires several alterations of our ways of understanding and evaluating businesses and their BMs.

As some forms of so-called SBM emerged (e.g. Sustainable Energy, Fair trade, Bottom of The Pyramid (BOP), Business recycling, Cradle to Cradle) many businesses began to rethink and change their business, BMs and BMIStrategies. The movement has developed from a so-called closed form of business (a firm, an entity, a business with a certain number of business models, not including the environment and the surrounding businesses) towards an open and sustainable form for business emphasizing the entire ecosystem of the business. This paper presents an exploration of the concepts and motivations involved in businesses moving from closed and none sustainable business models (NSBM) towards open and SBM. Thus, the research question of the paper is as follows:

"How can we identify sustainable business models and what are the incentives for engaging in sustainable business modeling?"

\section{Portfolio, Dimensions and Componens of the SB and SBM}

SB represents an ontology as a convention between network partner's sustainable businesses and BMs focusing and applied to the generation and sharing of SBMs and their values. The sustainability, and the radicality of 

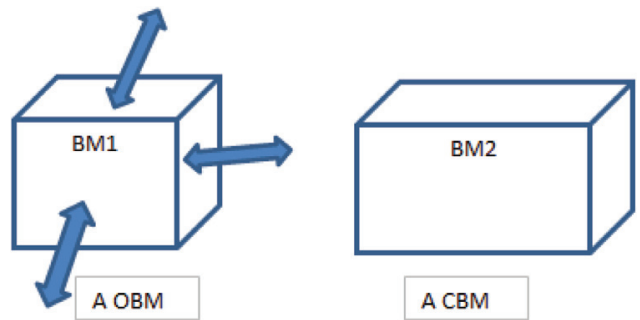

Figure 1 Flows in and out of a sustainable business model.

this sustainability, can however be very different from one SBM to another SBM. We propose that SBMs are fundamentally built in an equal way to NSBMs, comprising a variation of the 7 dimensions of a BM (Lindgren \& Rasmussen, 2013; Lindgren, Taran and Boer, 2010). The SBM is however different to the NSBM because it is specified as a given BM with a unique configuration of sustainability related to the none-SBM.

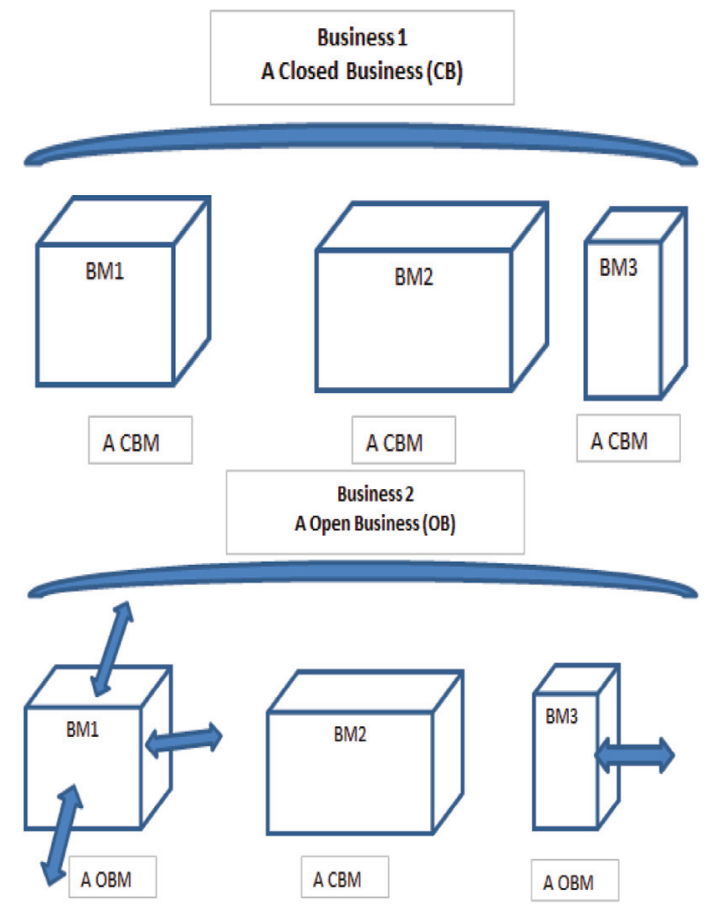

Figure 2 An example of a NSB and SB from a BM dimension perspective. 
It means that in an SBM, one or more of the individual dimensions and related components as shown in the figure beneath are sustainable. ANSBM by contrast has no sustainability in and out flows of values on any BM dimensions and components.

Seen from a business perspective, Business 1 has only NSBM and can therefore be classified as a non-sustainable business (NSB). Business 2 has both an SBM and a NSBM and therefore could be classified as SB to some extent. In most cases we believe that a BM is seldom fully sustainable or fully non sustainable.

\section{Incentives and Value Formula Related to SB and SBM}

SB communities reveal that financial rewards are not necessary enough to recruit and motivate SBMI, networks, business and BMs to join the SB and SBM. We have seen that communities, charity network, public bodies, event organisations, e.g. are not in particular motivated by profit and don't propose financial compensation to contributors of SB (Roberts et al., 2006). They have e.g. shown to be based on "bazaar" governance with open contracts, open asset, open workforce where control and incentives are very low (Demil and Lecocq, 2006; Nambissan and Sawney, 2007). The members tend to be more motivated by symbolic rewards such as recognition, branding, knowledge sharing, increasing their own knowledge, the feeling of solidarity, fairness and altruism (Roberts et al, 2006; Von Hippel and Von Krogh, 2006; West and Gallagher, 2006).

Von Hippel and Von Krogh (2006) propose an incentive model that combines elements of the private and collective models: the "private-collective" SBM model. Here, innovators in projects use their own resources to privately invest in the creation of new knowledge and in SBMI. Private investment and collective action can co-exist and enable the development of public value society value - through private funding. We believe the same could also be the case for SB and SBM innovation.

Chesbrough's framework on open business model (OBM) involves the use of deliberate inflows and outflows of knowledge - in our definition on SBMI - knowledge innovation (Amidon, 2011) would be highly useful to accelerate SBMI and to expand the BM Ecosystem for external use of SBMs. Chesbrough $(2006,2007)$ consider that a businesses' overall BM acts as a filter to select the BMs that fit the focal BM. Adapting this approach means that the SB and the SBM related to Chesbrough's proposal would be related to the business - which again questions the degree of sustainability related 
to the SB and SBM paradigm. Further it questions if there are other levels of SBM than the business - e.g. the BM Ecosystem, the society, the world and the process. These could be the filters on a scale of how sustainable the SB and SBM really is. We will come back to this in our final framework for judging the sustainability of the SB, SBM and SBMI.

Chesbrough $(2006,2007)$ also states that the OBM paradigm gives birth to a new type of business called "OBM innovation intermediaries". These businesses act as "market places" or OBM platforms, whose function is either to help BM innovators use external ideas of BM more rapidly, or help inventors find more markets or other business and BMs where others can use their own BM ideas and concepts in a mutually beneficial way.

\section{Motivations for SB and SB Modelling}

Defining a value creation model based on a SB and the SBM concept requires a good understanding of how to motivate contributors to ensure that they actively participate in the SB and SBM activities - and not just create, capture, deliver, receive and consume the sustainable values and leave any "non sustainable value" behind for others to deal with.

The first SB model is the private investment SBM model, where contributors to an open business and OBM are individually rewarded for the knowledge they provide by private, public, NGO's and non profit organisations or a mixture of all "investors". They expect to make profits or other values on top of the developed SBM's. Intellectual propriety is transferred from individual

A change to a network based BoP - combining knowledge, expertise and resources from end users / NGO's, companies and researchers so as to meet the evident demands in developing countries

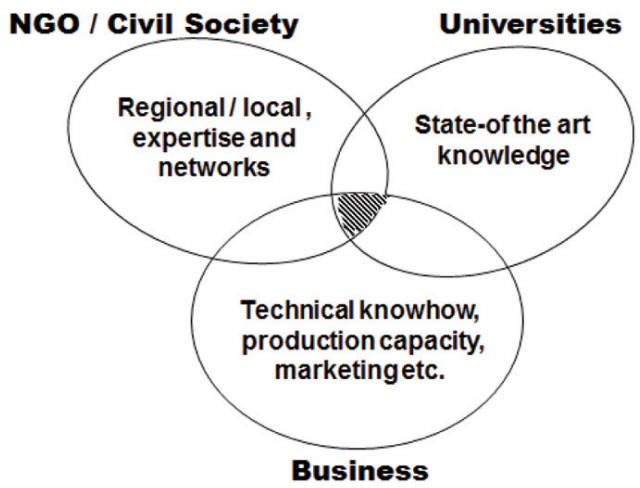

Figure 3 BOP business models. 
contributors to "investors" via patent, copyrights, futures etc. Private, Public and NGO BMs are together joining a BOP BM in a triple helix cooperation to create different types of value to each other and other in markets with no or very little money. According to research, one challenge to this first model is geographical distance (Lindgren et al., 2010).

The second model is the collective action SBM model. This model is based on the revealing of findings, discoveries and knowledge freely and openly in the business. It characterises fully SBMI, and above all sustainable value creation projects as examples of sustainable business model innovation. In so far as it makes collaborative sustainable value design possible the collective action model assumes that SBM innovators relinquish control of knowledge, or other sustainable value assets they have developed during the project, and so create sustainable value.

According to Von Hippel and Von Krogh (2006), one major problem of the collective action model is how to reward real contributors and how to avoid free riding (e.g. downloading of open source software without contribution). The same would be the case of SBMI. The literature on collective action related to SB and SBMs are very limited but there are some indications that the creation and deployment of selective incentives to reward contributors to SB and SBMs is essential to the success of collective action SBMI projects. The importance of selective incentives related to SB and SBM indicates that small groups will be most successful at executing collective action SBM because selective incentives can be carefully tailored to each group member, and individual contributions can be more effectively monitored. However this have consequences for the judgement and classification of sustainability.

\section{Discussion}

This study has explored the concept of SBMs and the incentive models for engaging in SBMI. However, a number of key issues need to be addressed in research to get a clear definition of SB and SBM. For one, can a business claim sustainability, if the business contains both sustainable and non-sustainable BMs? Another interesting question that needs explorations: how sustainable does a SBM have to be? Does the label, "SBM", require that all dimensions of the BM are sustainable? And who and which part of the network and ecosystem determines the level of sustainability? And finally is it at all possible to talk SBMs over time and in the long run, as what is considered sustainable changes with time? 
Exploring the Concept and Incentives of Sustainable Business Models 41

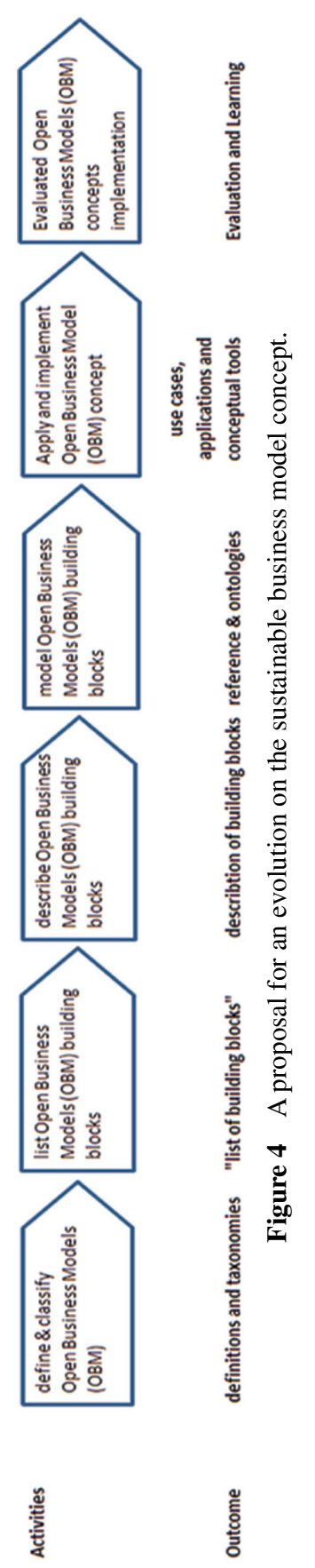


We have identified five core phases in the SBM literature, which could be followed in further exploring the concept and the motivation for SBM.

In the first phase, a number of suggested SBM definitions and classifications can be drawn up. State of the art analysis reveal that there is still some confusion on the definitions and taxonomy of SBM.

In the second phase we can begin to complete the SBM definitions by proposing what elements belong into a SBM and what does not.

The third phase will follow with a detailed description of these SBM components, SBM dimensions, SBM, SBM portfolio, SB, SBM Ecosystems and SBMI process to describe the SBM.

In the fourth phase researchers can begin to model the SBM conceptually culminating in a SBM ontology and finally,

In the fifth phase, SBM models can be applied into SBMI leadership and management and related information systems [practice] applications.

In this context an evolution platform on the SBM concept can be very helpful to illustrate the important role of SBM in a long-term perspective.

In this context our baseline analysis have shown that academically we have reach the last part of the first phase with some examples of what we think is SBM, SB and SBMI.

\section{Conclusion}

This study has discussed different approaches towards exploring and understanding SBM and the incentives of SBM, using Chesbrough's open and closed BM concepts as well as the incentive models: the "private-collective" SBM, the collective action SBM and the BOP SBM.

However, the lack of clear definitions and classifications of the SB, SBM and SBMI notion converge towards the approach that the SB are related to some vision and maybe in some cases to an SBM concept vision. It seems that nobody has dealt with a number of additional start-up and operational issues that transcend the SBM and furthermore, it seems that the vision of the SBM is not just one strategy but includes a number of SBM strategy elements.

We have in our baseline analysis approached the SB and SBM concept as a unifying unit of analysis and conclude from our cross-theoretical perspective that no single theory can fully explain SB and SBM. Consequently, it is difficult to identify a holistic framework for a generic SB and SBM depending merely on one SB and one author's perspective. The contributions from our baseline research show that we could however propose and identify some 
common ideas and theories of the SB and SBM with the following details and aspects:

"A sustainable business and its related sustainable business model are built upon ideas and concepts that advocated by the main theoretical framework of CSR and sustainability (Carroll, 1991; Elkington, 1997; Carroll \& Shabana, 2010) and the ideas and concept of the business model framework (Lindgren \& Rasmussen, 2013) to a SB, SBM and SBMI approach.

Since the existing sustainable business model perspective in general, but not in detail take into consideration the ways in which tangible and intangible values, value proposition dimensions and value proposition components of "non sustainable businesses", "non sustainable business models" and "non sustainable business model dimensions and components" can be valuable to other businesses and business models - we claim that the SB and SBM is still incremental in its thoughts, concept and operation related to sustainability and especially to what we think could be a radical SB and radical SBM. However the existing thoughts of "sustainable business" and "SBM" concept is a starting point but still difficult to imitate, less transferable, less substitutable, and less productive with use as it is formed now. It is fundamentally built on a business and business model framework that mainly has a resource-based view of a business and not on an integrated, network-based and relation-based view of a business and business model.

\section{References}

[1] Aagaard, A. (2012). CSR med succes - fra teori til praksis. Gyldendal, Copenhagen.

[2] Amit, R., and Zott, G. (2001). Value creation in e-business. Strateg. Manage. J. 22, 493-520.

[3] Carroll, A. B. (1991). "The Pyramid of Corporate social responsibility: toward the moral management of organizational stakeholders," in Business Horizons (Elsevier).

[4] Carroll, A. B., and Shabana, K. M. (2010). The Business case for corporate social responsibility: a review of concepts, research and practice. Int. J. Manage. Rev. doi: 10.1111/j.1468-2370.2009.00275.x

[5] Chesbrough, H., Ahern, S., Finn, M., and Guerraz, S. (2006). Business models for technology in the developing world: the role of non-governmental organizations. Calif Manage. Rev. 48, 48-61.

[6] Chesbrough, H. (2007). Business model innovation: it is not just about technology anymore. Strateg. Leadersh. 35, 12-17. 
[7] Chesbrough, H. (2010). Business model innovation: opportunities and barriers. Long Range Plann. 43, 354-363.

[8] Chesbrough, H., and Rosenbloom, R. (2002). The role of the business model in capturing value from innovation. Ind. Corp. Change 11, 529-556.

[9] Christensen, G. M., and Raynor, M. (2003). The innovator's solution, Boston: Harvard Business School Press.

[10] Demil, B. and Lecocq, X. (2010). Business model evolution: in search of dynamic consistency. Long Range Plann. 43, 227-246.

[11] Elkington, J. (1997). Cannibals with Forks: the Triple Bottom Line of 21 st Century Business. Oxford: Capstone Publishing Ltc.

[12] Garavan, T., and McGuire, D. (2010). Human resources development and society: human resource development's role in embedding corporate social responsibility, sustainability and ethics in organisations. Adv. Dev. Hum. Res. 12, 487-507.

[13] Govindarajan, V., and Trimble, G. (2005). Ten Rules for Strategic Innovators: From Idea To Execution. Boston, MA: Harvard Business School Press.

[14] He, N. (2012). How to maintain sustainable competitive advantages: case study on the evolution of organizational strategic management. Int. J. Bus. Admin. 3, 45-51.

[15] Inyang, B., Awa, H., and Enuoh, R. (2011). CSR-HRM nexus: defining the role engagement of the human resources professionals. Int. J. Bus. Soc. Sci. 2, 118-126.

[16] Lindgren, P. et al. (2010). "The conceptual understanding of BoP business model(s)," in 7th ICCSR Symposium - Corporate Social Innovation and Sustainable Community Development, Nottingham, UK.

[17] Lindgren, P., and Rasmussen, O. (2013). The business model cube. J. Multi Bus. Model Innov. Technol. 1.

[18] Lindgren, P., and Aagaard, A. (2014). The sensing business model. Wirel. Pers. Commun. 76, 291-309.

[19] Markides, C. (2008). Game-changing Strategies: How to Create New Market Space in Established Industries by Breaking the Rules. JosseyBass, Hoboken, NJ.

[20] Markides, C. (2013). Business Model Innovation: What can the ambidexterity literature teach us? Acad. Manage. Perspect. 27, 313-323.

[21] Markides, C, and Charitou, C. (2004). Competing with dual business models: a contingency approach. Acad. Manage. Exec. 18, 22-36. 
[22] Nambissan, S., and Sawney, M. (2007). A Buyer's guide to the innovation Bazaar. Harv. Bus. Rev. 109-118.

[23] Rosethorn, H. (2009). The Employer Brand: Keeping Faith with the Deal. Surrey, England: Gower Publishing, Ltd.

[24] Taran. Y. (2011). Re-Thinking it all: Overcoming Obstacles to Business Model Innovation Center for Industrial Production. PhD Thesis, Aalborg University.

[25] Taran, Y., Boer, H., and Lindgren, P. (2013). A business model innovation typology. J. Decis. Sci.

[26] Teece, D. J. (2010). Business models, business strategy and innovation. Long Range Plann. 45, 172-194.

[27] Zott, C, Amit, R., and Massa, L. (2011). The business model: recent developments and future research. J. Manage. 37, 1019-1042.

[28] Von Hippel, E. and Von Krogh, G. (2006). Free revealing and the privatecollective model for innovation incentives. $R \& D$ Manage. 36, 295-306.

[29] Wang, W., Lin, C., and Chu, Y. (2011). Types of competitive advantage and analysis. Int. J. Bus. Manage. 6, 100-104.

[30] West, J., and Gallagher, S. (2006). Challenges of open innovation: the paradox of firm investment in open-source software. $R \& D$ Manage. 36, 319-331.

\section{Biographies}

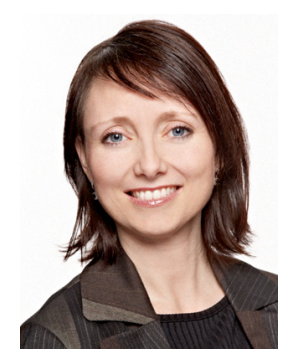

A. Aagaard is an Associate Professor at the Department of Business Development and Innovation at Aarhus. She holds a Ph.D. in Front End Innovation in Pharma \& Biotech and has interests within the scientific fields of management, innovation and CSR drawing on experiences in the academic, public and private sectors, where she was formerly a manager and management specialist for twenty years with experiences from numerous large organisations. Through her elaborate network she performs and provides empirical research with 
the main objective to bridge the gap between theory and practice. She has been a lecturer for almost two decades within innovation \& entrepreneurship, CSR and change management for almost two decades, and has authored ten academic books and several journal articles on different innovation, management, knowledge sharing and CSR topics.

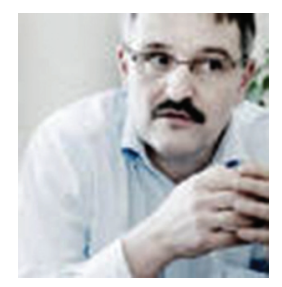

P. Lindgren holds a full Professorship in Multi business model and Technology innovation at Aarhus University, AU Herning and has researched and worked with network based high speed innovation since 2000 . He is author to several articles and books about business model innovation in networks and Emerging Business Models. He has worked as a researcher at Politechnico di Milano in Italy (2002/03) and Stanford University, USA (2010/11) and has in the time period $2007-2010$ been the founder and Center Manager of the International Center for Innovation www.ici.aau.dk at Aalborg University. He works today as researcher in many different multi business model and technology innovations projects and knowledge networks. 